\title{
'IT OPENED MY EYES TO THE PROBLEM OF STIGMA ON CAMPUS': TRAINING ART STUDENTS TO BE HIV STIGMA COMMENTATORS
}

\author{
C. Volks* \\ Director: HIVIAIDS, Inclusivity and Change Unit \\ e-mail: cal.volks@uct.ac.za \\ L. Reddy* \\ HIVIAIDS Inclusivity and Change Unit \\ e-mail: lucina.reddy@uct.ac.za
}

\section{F. Saptouw*}

Michaelis School of Fine Art

e-mail: f.saptouw@uct.ac.za

*University of Cape Town

Cape Town, South Africa

\section{ABSTRACT}

In an attempt to create an AIDS-competent community at Higher Education Institutions (HEIs), it is critical to connect HIV and AIDS curricula and co-curricular initiatives with communication campaigns that reach students who may not self-select to attend HIV and AIDS workshops. To this end in 2012, UCT ran four communication campaigns with concomitant anti-HIV-stigma peer education workshops for students on campus. This article provides insight into the initial teaching project developed and designed by the Michaelis School of Fine Art and HAICU (HIVIAIDS, Inclusivity and Change Unit) at the University of Cape Town to engage students in understanding the lived reality of HIV positive students on the campus. Initial findings from a focus group with first year fine art students indicate that the project is a great vehicle towards getting students to engage with what would be termed previously studied areas such as HIV. After this project's success the model utilised by the project team has been taken up by other departments at the University and possible further interdisciplinary collaboration for teaching students are being discussed.

Keywords: Communication Campaigns, initial teaching project, anti-stigma, first year students, interdisciplinary

\section{INTRODUCTION}

HIV and AIDS and inclusivity have been a major issue for HEIs in South Africa as outlined 
in the HEAIDS 2010 report on HIV prevalence at Higher Education institutions (HEAIDS 2010, 1). While a number of research, outreach, management, prevention and support programmes are in place at the University of Cape Town (UCT), in the current environment, despite increased opportunities for HIV treatment, only two HIV-positive UCT students have publicly declared their HIV status between 2003 and 2013. It is widely acknowledged that fear of stigmatisation is a strong motivating factor in non-disclosure (Campbell, Skovdal, Madanhire, Mugurungi, Gregson and Nyamukapa 2011). Non-disclosure may be indicative that discrimination and stigmatisation are ongoing issues at UCT. 'Particular negative effects [of stigma] have been identified in 'culturally defined out groups', among whom HIV and AIDS-related stigma has led to many of those infected and affected withdrawing from social contact with others altogether' (Asingwire 1992, in UNAIDS 2001, 16). Self-stigmatisation is also a problem. 'Beyond the enacted (experienced) stigmatisation and discrimination ... perceived stigma' can lead 'individuals to police their own behaviour to prevent their serostatus from becoming known to others’ (UNAIDS 2001, 21). This may account for why UCT students continue to not access support mechanisms within the institution.

In addition, to the discussions above, given that the generation at UCT between 2003 and 2013 grew up in post-apartheid South Africa, and that a significant number of Black students in this group are the first generation in their families to attend tertiary education (something for which their parents' generation made great sacrifices for in the liberation struggle). It would be highly detrimental to transformation if HIV and AIDS became a new form of exclusion that inhibited the full participation of HIV-positive students in the social and academic life of UCT, in graduation and, ultimately, in gaining employment. This makes addressing HIV and AIDS stigma a critical aspect of managing inclusivity among students. However, the vast majority of HEI HIV and AIDS programmes focus on HIV and AIDS solely as a health issue, allocating resources to HIV testing and referral for ARVs only, without adequately addressing HIV stigma. Coupled with this, staff members at UCT Student Wellness and HAICU (HIV/AIDS, Inclusivity and Change Unit) have reported anecdotally the experiences of HIV-positive students as told to them during individual consultations. These reports indicate that students have been unwilling to either publicly or on a one-to-one basis disclose their HIV status (even to other students who are HIV positive) for fear of being stigmatised. As part of addressing the perceived barrier HAICU installed a free helpline service for students. Students could call the helpline with questions while retaining anonymity. Through this helpline, students were able to get information about HIV as often as they needed even though they were not ready to attend a face-to-face support group. HAICU 
also ran an anonymous online support group from 2003 to 2004, where HIV-positive students could anonymously chat to other HIV-positive students. In this forum students reported that they did not feel comfortable to meet face-to-face for fear of being stigmatised publically by what they perceived as a non-inclusive student campus.

In the past it was believed that by putting HIV-positive people onto ARVs, stigma would disappear. Despite increased knowledge about HIV and AIDS within the student population and improved access to ARVs for people living with HIV, HIV stigma persists as an issue on HEI campuses and at UCT. HIV stigma continues to reinforce pre-existing lines along which people discriminate, such as race, class, gender and sexuality (Parker and Aggleton 2002 ,5). Campbell, Nair, Maimane and Nicholson (2007) remind us that stigma is a complex, multidimensional entity and that strategies to reduce stigma need to address these different levels.

In 2006 HAICU adopted Catherine Campbell's theories of an AIDS-competent community and of peer education as the programme theory for its work. HAICU's vision for UCT is: 'a transformed, AIDS-competent UCT community addressing HIV and AIDS in Southern Africa' (HAICU 2012, 1). The mission of HAICU is: 'to coordinate a collaborative response that supports UCT transformation and builds student and staff capacity through curriculum, co-curriculum (peer education) and social responsiveness initiatives' (HAICU 2012, 1). In line with applying Campbell's theory to the goals of HAICU to build an AIDScompetent community, the research-based, broad strategic objectives of HAICU are: 'building knowledge and skills; creating safe social spaces for dialogue; promoting ownership and responsibility; building confidence in local strengths, and agency to mobilise these; building solidarity ("bonding” relationships); [and] building partnerships (“bridging” relationships)' (HAICU 2012, 1).

In striving to create an AIDS-competent UCT, one component of HAICU's strategy to achieve its objectives is to conduct HIV/AIDS communication and social awareness events on UCT campus. These are aimed at the broader UCT community and are intended to challenge entrenched beliefs, provoke debate and facilitate enhanced awareness of issues leading to HIV stigma and possible ways to overcome this.

\section{THE HISTORY OF VISUAL REPRESENTATIONS OF PEOPLE LIVING WITH HIV AND SUPPORTING PEOPLE WITH HIV}

In order to understand the underlying principles of the university's communication campaigns it is important to provide a brief history of visual representations of people living with HIV.

In the era prior to widespread access to ARVs, there were numerous visual 
representations of people with AIDS published in newspapers and at photographic exhibitions. These were images of impoverished, emaciated, terminally ill African people in resource-poor settings. The intention may have been to illustrate the harsh reality of many people living with AIDS in Southern Africa and to shock the public, particularly when the South African government refused to provide ARV treatment. However, these images served to further stigmatise people living with HIV and AIDS, invoking fear and 'othering' of people who contract HIV (Joffe 1999, 1-17). The photographic representation of HIV in Africa has been dominated by images that shock the viewer with the depiction of human suffering. There is considerable critique of such 'horror images' and the way they show African subjects as nameless victims who appear unable to save themselves from certain death (Kleinman 1997, 1-11). Such images are problematic for a number of reasons, such as the perpetuation of stereotypical representations of the African subject by the international media. While some stereotypes are based on elements of reality, they tend to limit analysis of the greater context and usually absolve the viewer from any engagement with the issue beyond passing pity or grim fascination (Wienand 2014).

Following on from the early depictions of HIV, ARVs were introduced in the 2000s in the Western Cape through the Medicine Sans Frontierés (MSF) (Doctors without Borders) clinic in Khayelitsha in the Western Cape. Photographer Gideon Mendel (2010) compiled a photo essay of HIV-positive people who had access to ARVs through the MSF clinic. His work foregrounded HIV-positive people who appeared 'healthy' and 'happy', demonstrating the efficacy of ARVs. These photographic themes reflect the biomedical and legal struggle for access to treatment for people living with HIV. However, people with HIV have many identities between 'very sick' and 'very well'. More diverse identities have not often been captured in still photographic images, although the film series, Steps for the Future (Steps for the Future 2016) includes a wonderful collection of footage of various people living with HIV, as does the Siyanqoba Beat It series (Johnson 2010).

Since 2000 Gisele Wulfsohn and Santu Mofokeng (Wienand 2014) have undertaken the task of photographing HIV-positive people. Their work has attempted to draw South Africans' attention to the reality of HIV in South Africa without creating victimhood. However, these images were not specifically of university students and a need arose to specifically focus on this population.

In creating campaigns depicting people living with HIV, HAICU staff considered carefully the images of HIV that were to be presented. In 2006 and 2007, there was an attempt to allow for a more complex engagement with people living with HIV. HAICU did not want 
to show HIV-positive people as images just to be looked at, but to convey something of the complexity of their experiences of stigma (for example, in one campaign where paper birds were placed in trees on the campus. The birds were not just the birds, but the birds attached to haiku poems and similarly in the mask campaign - the people behind masks were not just people, but people expressing the difficulties of disclosing). In another campaign, the 2008 Stop Stigma campaign, HAICU staff wanted to take the focus off HIV-positive people and take those who were being viewed - people affected who are proud to support eradicating HIV stigma - to create a context of solidarity and desired social identities. In all these campaigns HAICU staff wanted to find a way of engaging the university community members in an interactive way.

\section{HAICU'S HIV DE-STIGMATISATION COMMUNICATIONS CAMPAIGNS}

In trying to facilitate this interaction HAICU staff employed the entertainment-education (enter-educate) or edutainment approach on a number of occasions to promote both HIV prevention (e.g. condom use and HIV testing) and support for people living with HIV. Edutainment has been described as a strategic process to design and implement a communication form with both entertainment and education elements to enhance and facilitate social change (Colle 2000).

While trying to incorporate Colle's edutainment approach and when addressing HIV stigma through a communications event on UCT campus, HAICU staff were cognisant of limited time within which to compete for students' attention. Within these constraints, HAICU staff attempts to communicate the idea of de-stigmatising HIV in a general sense at the event and further attempts to create a space to communicate more complex ideas in the facilitated peer education workshops. These activities form part of a broader university campaign that is run for a term. At the workshops students work through understanding what Maughan-Brown $(2004,5)$ terms 'instrumental stigma', and look at the contexts in which HIV stigma develops as well as ways to address it. It is preferable for students to attend both the communications event and the related workshops, to unpack the complexity of instrumental stigma and the contexts that give rise to it. However, some students will only attend the event and, therefore, the goal of an event should include making students aware that communities shape contexts within which HIV stigma can thrive or not thrive (and that stigma is not only about individual points of view). However, campaigns and events' outcomes are not always clear and HAICU staff needed to measure if the message was being received and implemented. 


\section{STUDENTS' RESPONSES TO THE HIV AND AIDS ANTI-STIGMA CAMPAIGNS}

HAICU (HAICU 2009) staff, in 2009, together with Southern Hemisphere Consultants, conducted an evaluation of how students experienced HAICU communication campaigns. The evaluators gathered data from questionnaires administered to students and through the implementation of in-depth interviews and focus groups.

The study findings showed that students who attended the events or participated in a campaign were able to understand the role stigma played in students feeling alienated on the campus as well as fearful to disclose their HIV status. The findings also indicated that students did not feel like the university was an inclusive space and more needed to be done to facilitate the building of an inclusive safe space for students (HAICU and Southern Hemisphere 2009, 4).

Further to the initial main findings students felt that campaign messaging needs to be nuanced and interactive. Students indicated that whilst posters had a primary role in delivering the message other means of communication should be employed to convey the campaign messages (HAICU and Southern Hemisphere 2009, 4). In 2012, based on the findings of this study and HIV stigma research, The Michaelis School of Fine Art First Year Lecturer and Course Convenor and HAICU staff started collaborating to develop a teaching project that integrated public artworks and HIV and AIDS awareness.

\section{THE 2012 ART INSTALLATIONS AROUND HIV STIGMA}

The teaching project included a series of lectures given by both the Michaelis Staff and the HAICU staff. The process starts with a lecture on the relevant social issues and a discussion of artworks that students can use as inspiration for their own artwork. Students individually research artworks and how to adapt it to make it relevant for a contemporary South African audience (Reddy and Saptouw 2015). Students are then divided into eight groups and tasked with the creation of temporary artistic interventions on the main campus of the University of Cape Town. Students are given approximately one month to generate an artwork for display in specific pre-selected public venues on the university campus. The development of the installations was intended to encourage other students to think about HIV stigma, not just as a health issue that required students to get tested for HIV or to learn more about how they could protect themselves, but also as an issue of diversity, inclusivity and social cohesion.

The artworks of the first year students were installed on 12 May 2012 at the University’s 
Candlelight Memorial Campaign which was held at the University Jameson Plaza, a central congregating point for students on the university campus. The artworks were place in and around Jameson Plaza and Molly Blackburn Hall (adjacent to the Plaza) and formed part of the messaging for the Candle Light Memorial Campaign for the university. The artworks were installed here so that students from all university faculties would be able to interact with the art. HAICU staff, fine art students and staff, and ACEs peer educators interacted with passing students about the installations. As this was the first implementation of this teaching project, no evaluation data was captured from the fine art student interaction with students. However, what the project team did retain were photographs of the group installations. In the next part of the article the project team will seek to articulate what the first year students were hoping to convey with their installations.

All the photographs of the installations were taken by Paris Brummer, one of the Michaelis Fine Art students. Permission was also given by the first year students to allow the project team to use their project proposals and the images of their installations.

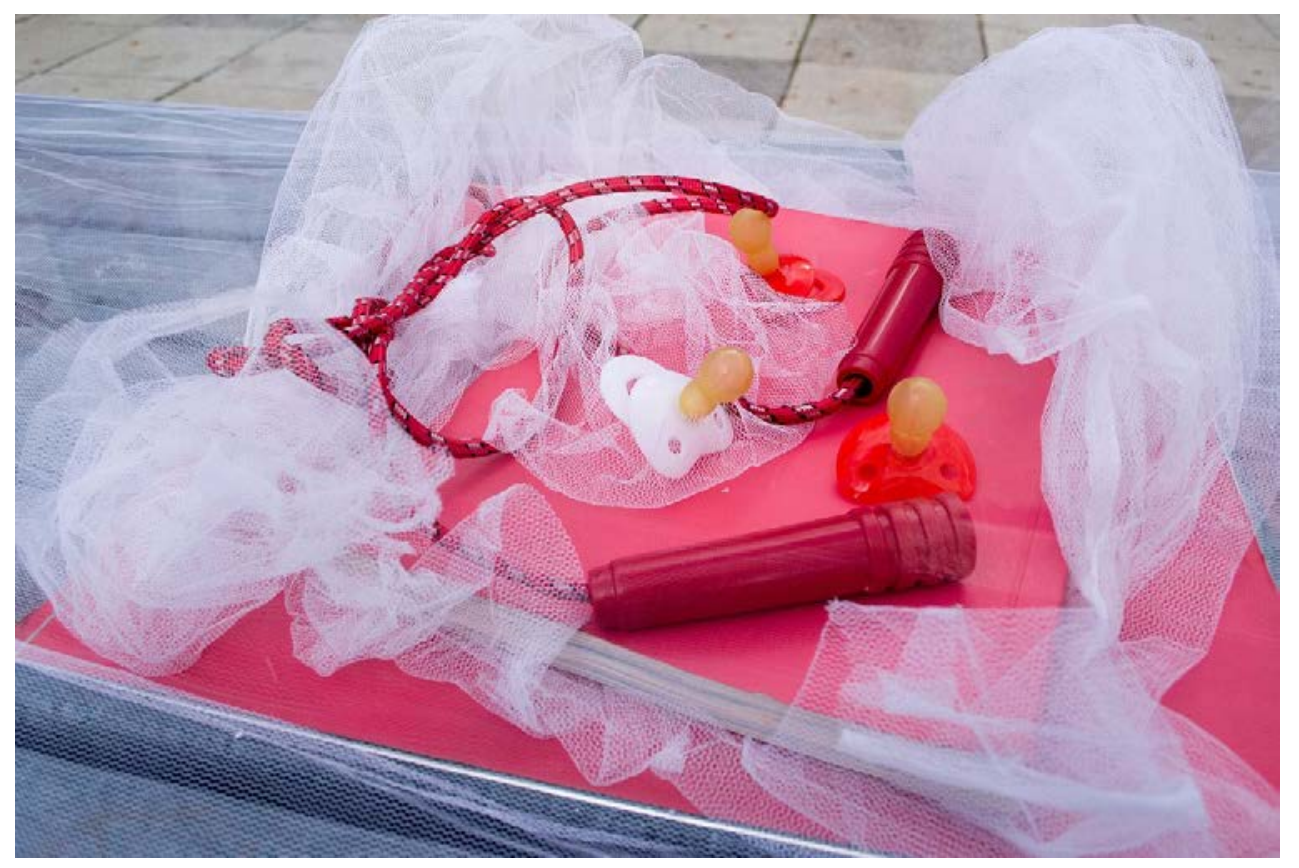

Photograph 1: Daniel Joubert, Julia Kabat, Bronwyn Katz, Kyu Lee, Melani Louwrens, Nomonde Magadla. Jenna-Lee Maitland, Dumelang Makhooane, Daniel Malan. 2012. The HIV Stigma Project. Misconceptions, Organza, Perspex, found objects, clay, paint, Size variable, Temporary installation, Photo by Paris Brummer.

The group presented a collection of items in two perspex squares that were placed on an outdoor table at the edge of Jameson Plaza, close to the Arts Block (now AC Jordan Building). The objects were items that members of the public were familiar with like books, dummies, a wedding ring and a jump rope. The contents of the squares were identical, except 
for the inclusion of a small sculpture of antiretroviral medication crafted by the students in the container on the left. Viewers needed to examine the contents of each square very closely to spot the difference. The group wanted to remind viewers that being infected with HIV and AIDS is not a death sentence, and that you can live a fulfilled life.

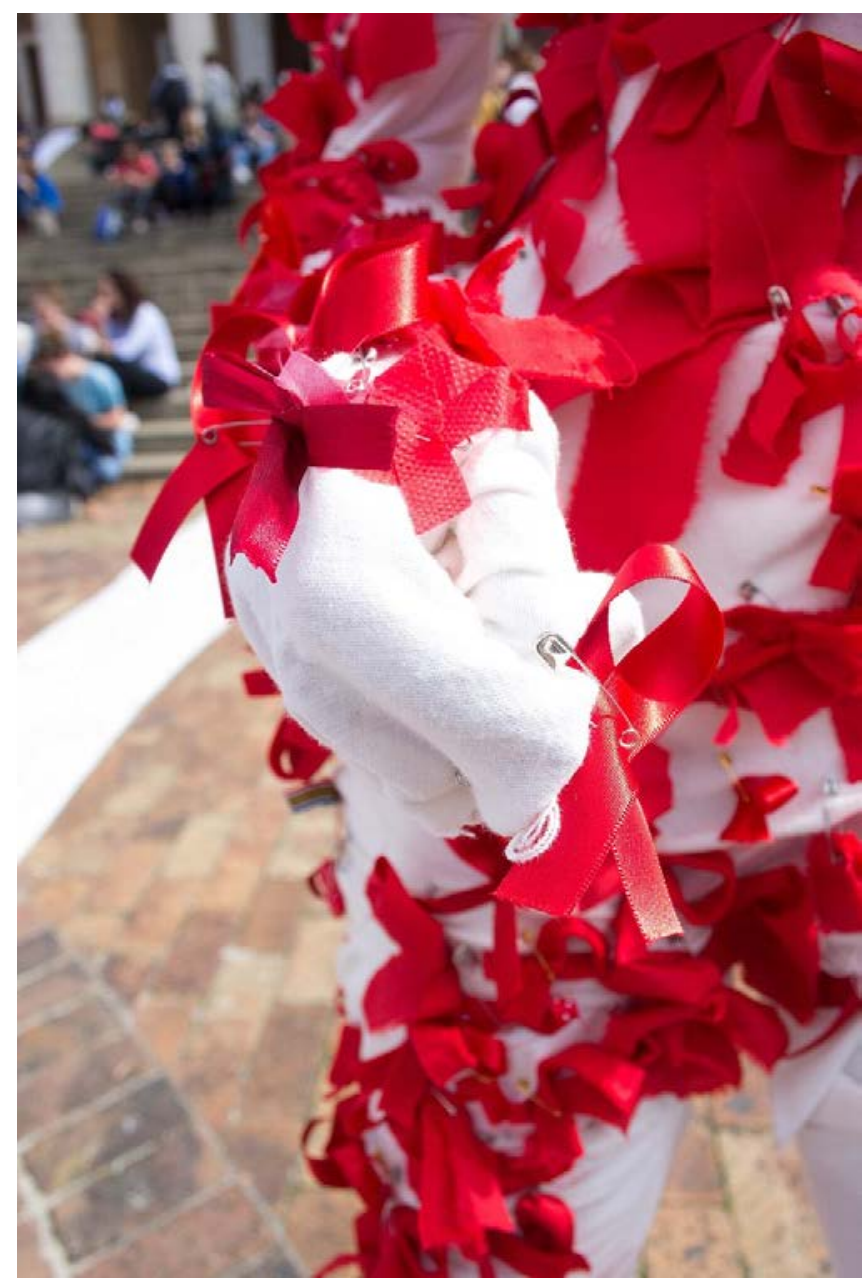

Photograph 2: Amy Spring, Ruby Swinney, Vanessa Tandwe, Ashleigh Tasker, Lauren Theunissen, Kim Wagner. 2012. The HIV Stigma Project. Mannequin, Mannequin, Red Ribbons, Safety Pins, White fabric. Size variable, Temporary installation, Photo by Paris Brummer.

This group wanted their artwork to make the audience aware of the power of acknowledging and restoring human dignity. The work acts as a reminder to those who are HIV-positive that their community can accept and support them. The initial image is quite shocking because the red ribbons seem to overwhelm the figure, but through audience participation this initial assessment changes. Students mentioned that 'the reason for using the AIDS ribbon symbol is that it is universally recognized as the symbol for the fight against AIDS' (Michaelis-HAICU Collaborations 2012). By taking a ribbon off the mannequin and wearing it for the day; the audience can publicly declare their support for those students finding it difficult to understand 
their HIV positive diagnosis. As the day progressed and more audience members engaged the artwork, the number of ribbons is decreased and the concealed 'human' form was revealed. This gesture tries to communicate the hope the community can give a HIV-positive individual by providing support and remembering the human 'behind the disease'.

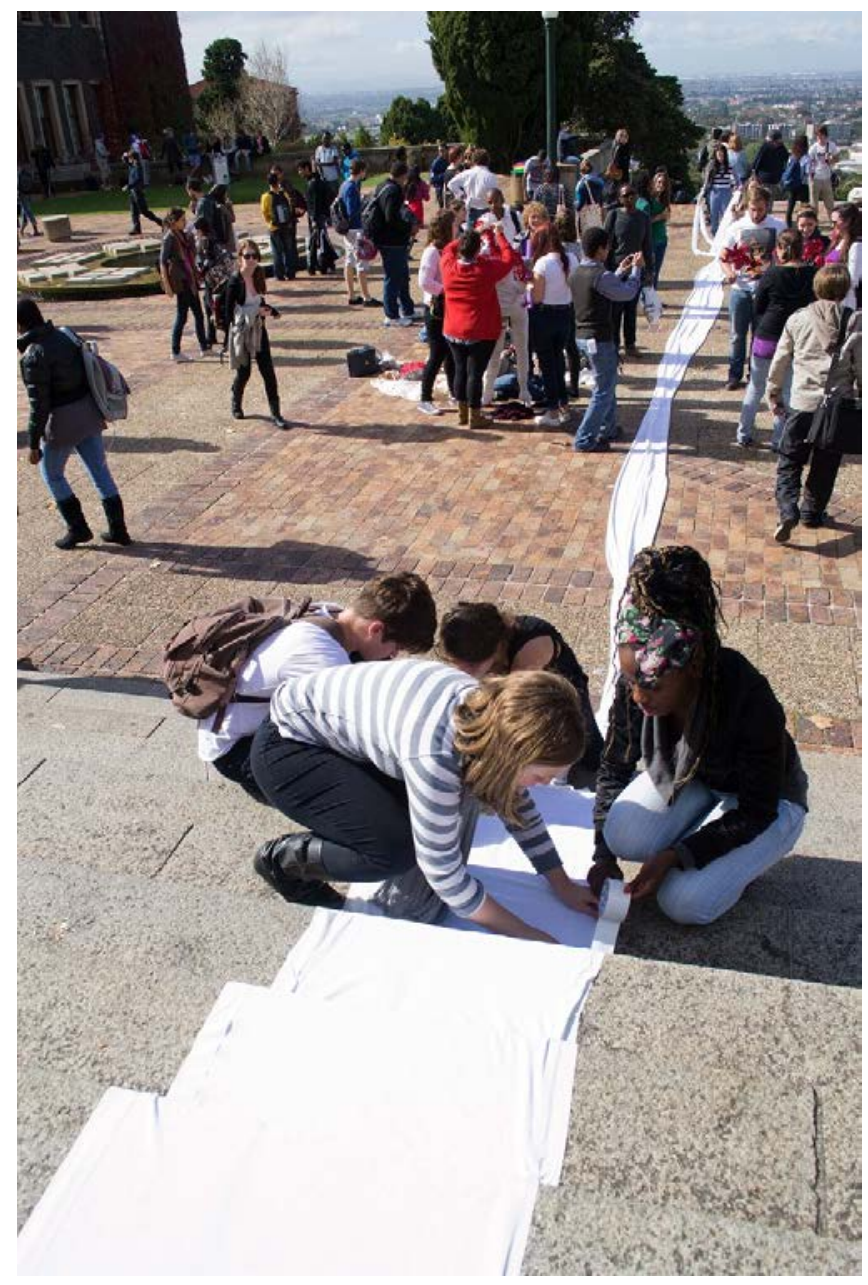

Photograph 3: Elizabeth Nkoana, Saskia Opperman, Dani Paul, Bert Pauw, Daniela Puccini, Meso Qhobela. Cameron Shefer-Boswell, Danielle Smith, Xanthe Somers, Anna Van Der Ploeg. 2012, The HIV Stigma Project. Footprints, White fabric, Red Paint, Double Sided tape, Duct Tape. Size variable, Temporary installation, Photo by Paris Brummer.

A long piece of white fabric was installed on the steps that connects Jameson Hall to the plaza area below. A few red footprints were placed on the cloth by the students, and viewers were provided with paint to contribute their own footprints to the project. The artwork was intended to make the viewers question what traces they leave behind and focus on our similarities and not our differences. While there may have been minor differences in shape and size, the footprint was taken as an inclusive representation of the diverse UCT student population. 


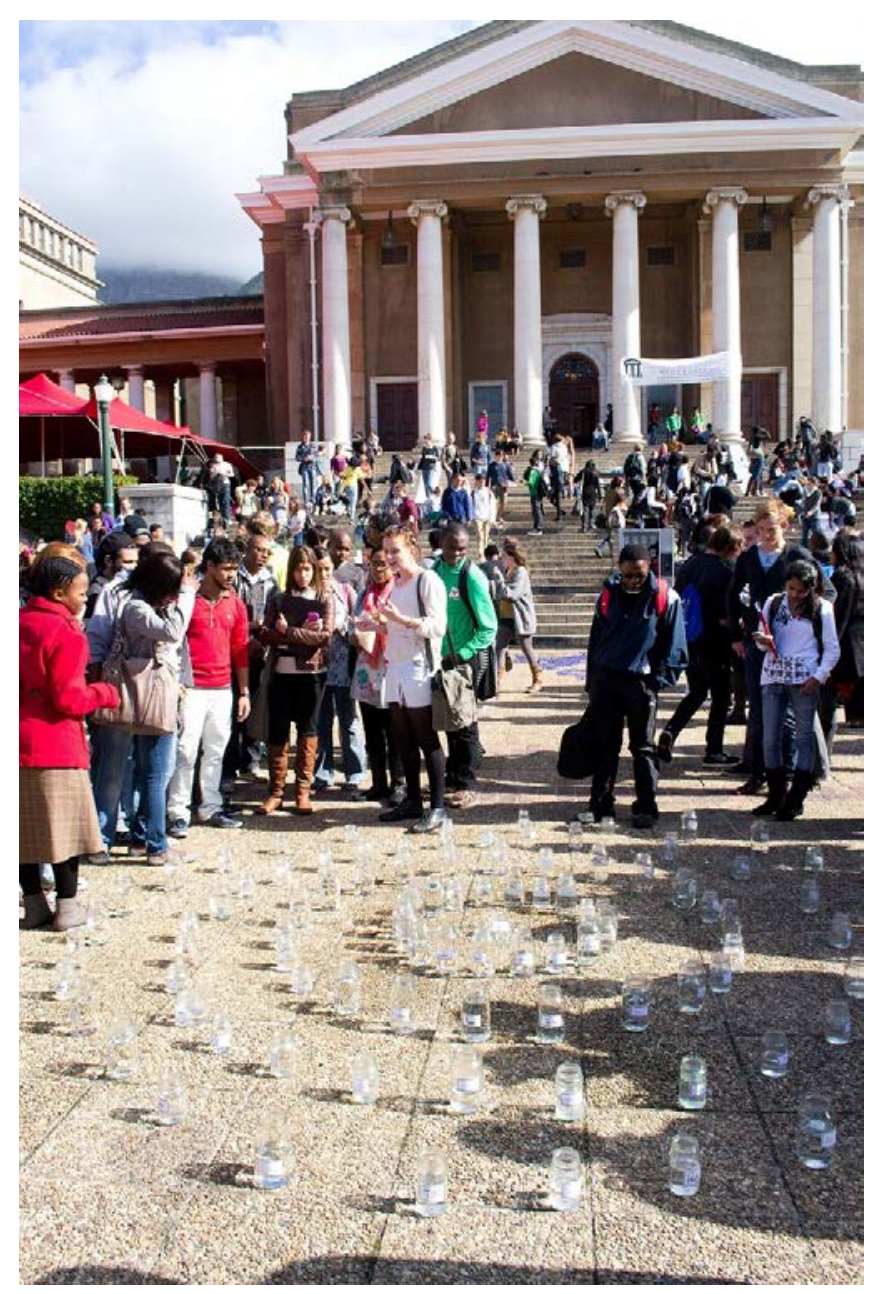

Photograph 4: Helen Aadnesgaard, Emily Allan, Kirsten Arendse, Michelle Aucamp, Kylie Ballantine. Frances Black, and Paris Brummer. Photographs: Paris Brummer. 2012, The HIV Stigma Project. Fountain, Tap water, Glass jars (various sizes), Self-adhesive Labels, Ink, Size variable, Temporary installation, Photo by Paris Brummer.

For this project the students filled glass jars with water and arranged them in a series of circles. Each jar was labelled with the name of an acquaintance within the group members' social circles. A single smashed jar was placed in the centre of the artwork. The work attempts to visualize how stigma is experienced in social circles. It was crucial for the students that they were able to draw on their own social environment to create a work that speaks to their everyday experiences.

The work in photograph 5 featured a series of 'flowers' recycled from cut and crushed empty cans. Each member of the group was tasked with the creation of their own group of flowers to give the artwork more visual diversity. A material shift is registered when the viewer encounters something that is aesthetically pleasing but also potentially dangerous. In addition, there is a tension between the organic and impermanent flower as opposed to the more permanent metallic can that is linked to waste and pollution. 


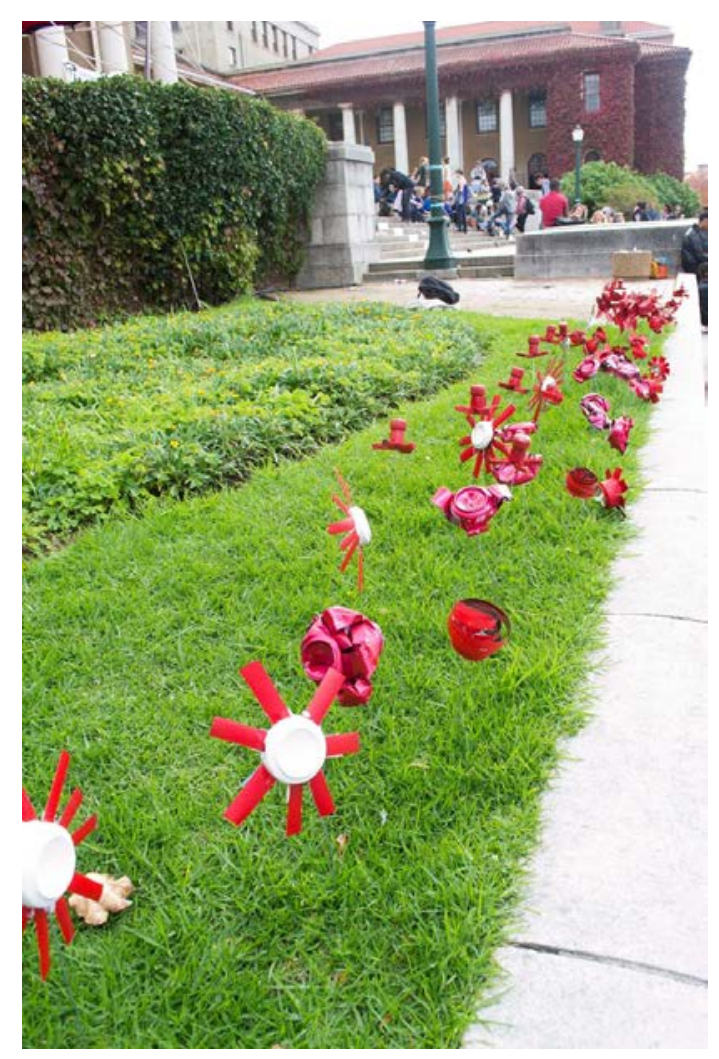

Photograph 5: Ruan Maree, Jane Matthews, Pola Mazus, Jess Metcalfe, Siwa Mgoboza, Caitlin Mkhasibe, Gitte Moller, Pamela Mulock-Bentley. 2012, The HIV Stigma Project. Flowers, Altered tin cans, Wire, Glue, Red paint, Size variable, Temporary installation, Photo by Paris Brummer.

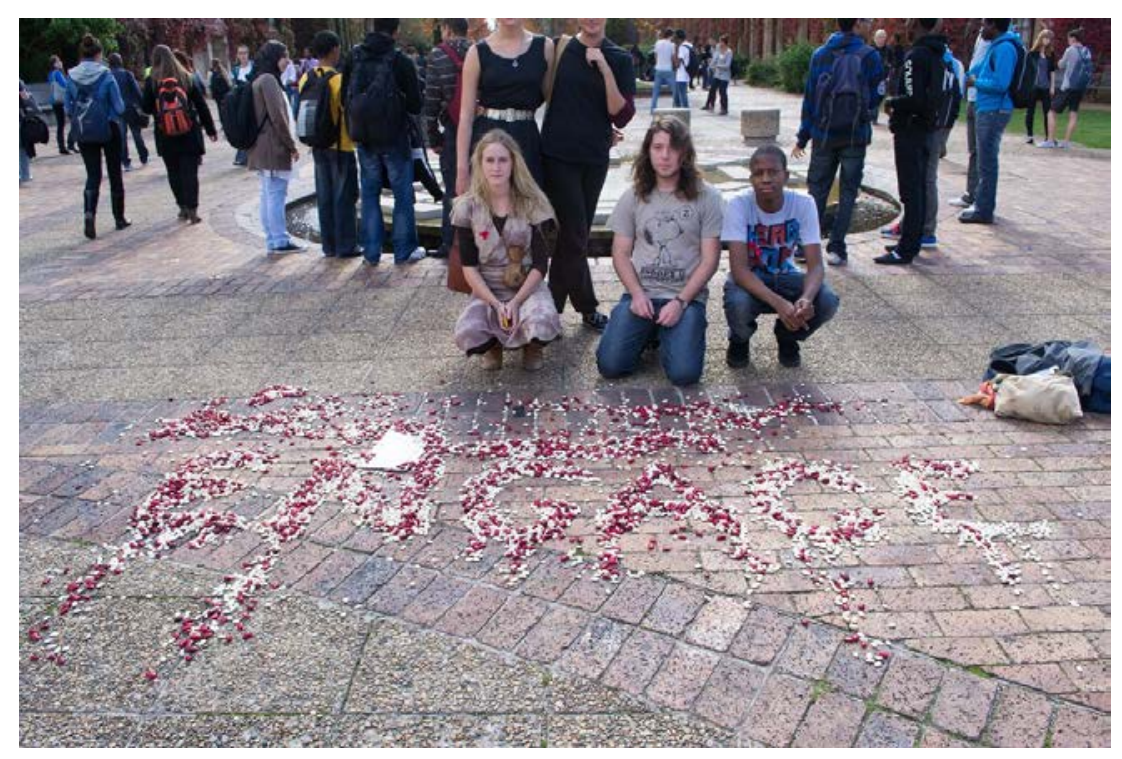

Photograph 6: Martin Wilson, Michaela Younge, Kylie Wentzel, Clara Wyma, Eileen van Aswegen, Katlego Tlabela. 2012. The HIV Stigma Project. Beans. Red and White Beans. Size variable, Temporary installation, Photograph by Paris Brummer.

This artwork allowed audience to create their own message instead of having an external party speak for them. The red and white beans were selected primarily because of two factors. 
The first was that they were items that could be easily found in many South African households. The second was that the colours echoed the HIV and AIDS awareness messages. The group's intention was to create a space for a discussion about the issues surrounding HIV and AIDS in the contemporary moment.

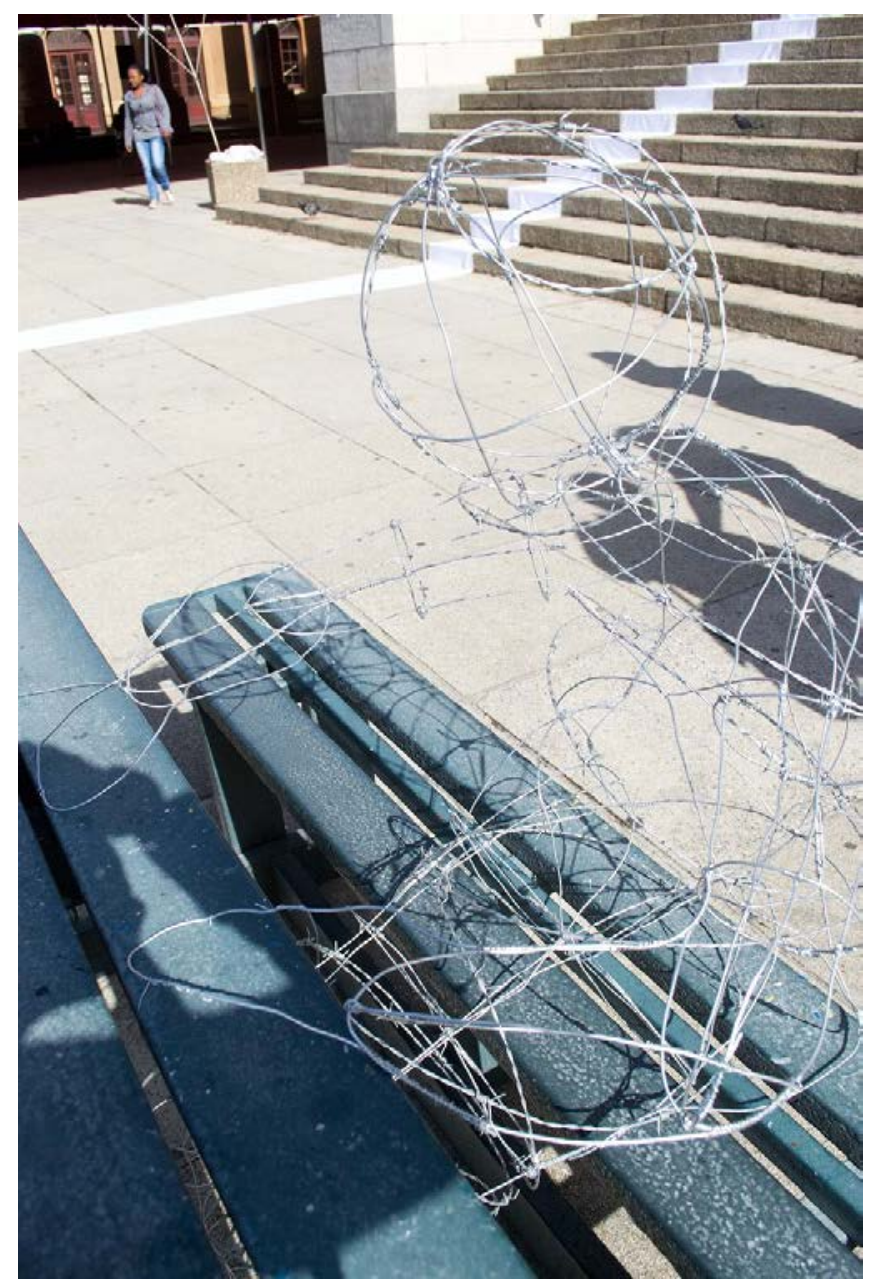

Photograph 7: Michael Goldsmid, Susan Greeff, Rupert Green, Sandy Harris, Caitlin Hocking. Mikayla Humphries, Lindi Jansen Van Rensburg. 2012. The HIV Stigma Project. Barbed-wire Figure, Barbed-wire, wire, Temporary installation, Photograph by Paris Brummer.

In the group proposal the students noted that 'the stigma of HIV and AIDS cannot exist by itself - it is maintained by the presence of the HIV positive, and by the fear of many who are not.' (Michaelis-HAICU Collaborations, 2012, 1). To communicate this idea, the group sculpted a human figure with barbed wire (affectionately referred to by the group as barbedwire bob) and placed him on a bench on the plaza. The students on campus were initially very fearful of the sculpture, but over the course of the day realized he posed no immediate danger and proceeded to sit next to him, take photographs with him, and according to rumour coopted him for their room in a UCT residence. 


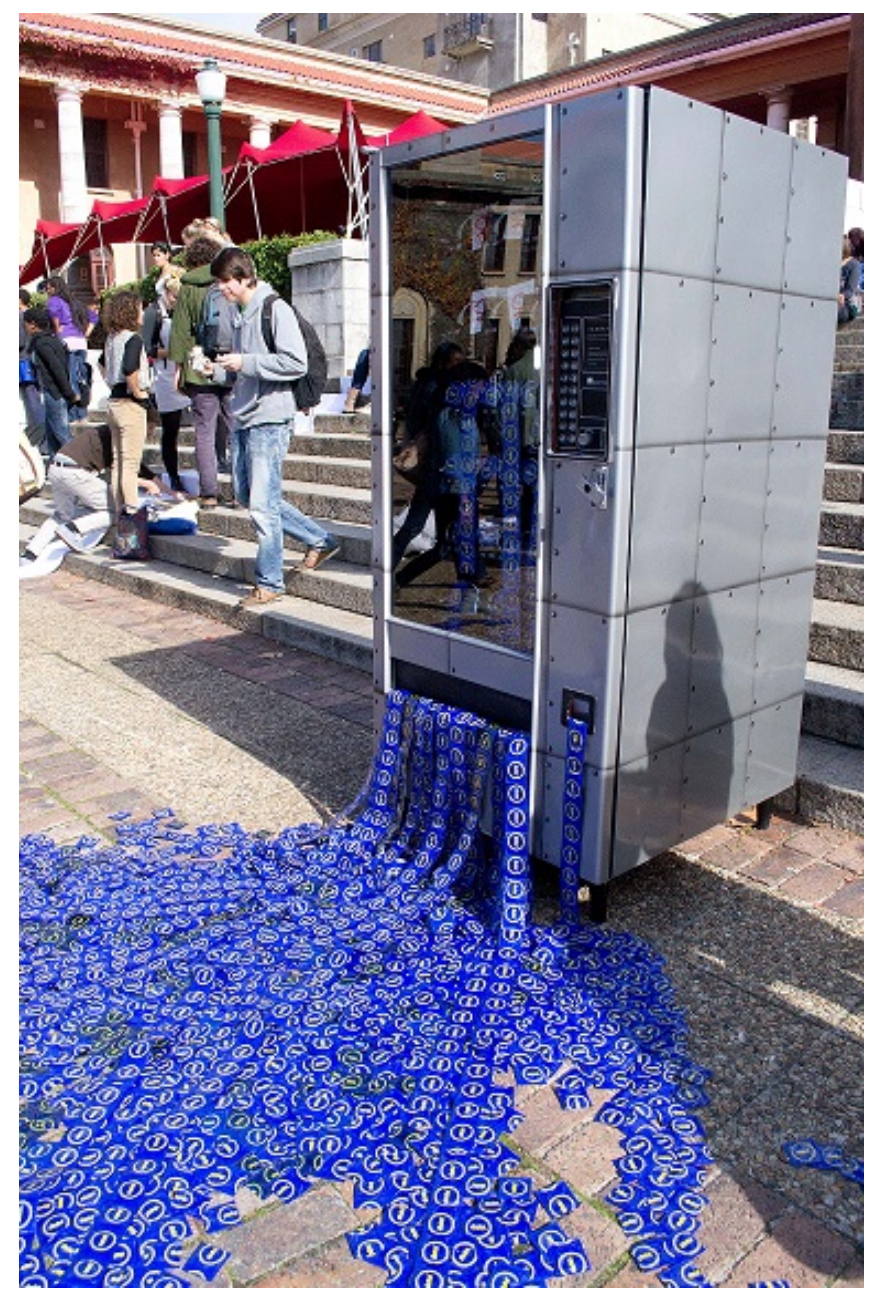

Photograph 8: Chiedza Chimwaza, Laura Chittenden, Jolandi Coetzee, Kasey Davies, Elize De Beer, Tamsyn Dodds, Cleo Du Plessis, Kate Eriksen, 2012. The HIV Stigma Project. Vending Machine. Choice, Condoms. Vending machine. Size variable, Temporary installation, Photograph by Paris Brummer.

The installation involved the use of a candy vending machine placed in the middle of the second level of the Jammie Steps in front of Jameson Hall. A stream of Choice condoms gushed from the dispensary section of the machine. The work was very effective in making the viewer aware of notions of the differing levels of public and private comfort related to sexuality. The students said, 'We want people to treat the use of a condom with the same ease, habit and thought as what people would buy a Coke from a vending machine or a packet of chips. We are taking the condoms out of a private area into public one, making the view aware of the condoms in a dramatic way.' (Michaelis-HAICU Collaborations 2012, 4). Special care was taken by the students to ensure that no one attempted to collect the condoms used in the artwork for sexual intercourse as they were glued together and exposed to the sun for a prolonged period of time.

After the project was implemented the project team wanted to understand how the 
students viewed the project. With this lens the project team conducted a focus group with the fine art students about their experiences and their feedback after the event and a summary of the initial findings are discussed in the next section.

\section{EVALUATION OF THE 2012 ART CAMPAIGN}

The purpose of this focus group was to ascertain what the art students had learnt during the implementation of this component of the first year course. The results of the focus group were analysed using grounded theory (Strauss and Corbin 1990). Through the analysis of the focus group data the project team were able to group the responses into four thematic areas: the students' knowledge of HIV after the project; the students' understanding of the relationship between HIV and AIDS and art; the use of art as a medium to educate students with a specific focus; and the method students used to develop art in response to HIV. In the section that follows the project team describes the thematic findings of the focus group with the art students.

\section{Students' knowledge of HIV after the project}

In this first theme some students indicated that prior to working on this curriculum based project they were not acutely aware of the HIV related stigma in their immediate surroundings. Through this project they were able to articulate that they need to begin to change their mind sets about how they view or represent people living with HIV. One student indicated this by saying:

To learn that people actually look down and stereotype people on campus, Wow! This project actually brought it into our everyday [lives] .... It was quite nice as it put it into a personal perspective. (Focus Group Participant 1) (Reddy 2012, 2).

Whilst this project aimed to address one of the HIV related issues on campus it also achieved its purpose of introducing what has previously been termed by students as 'a subject area they already knew about'. The project premise of using UCT students' experiences of stigma on campus helped the first year students to learn about the barriers that continue to exist on the campus. However, while the students were able to go on this journey of self-discovery it was not always the case.

\section{Students' understanding of the relationship between HIV and AIDS and art}

Initially students struggled to see the link between HIV and AIDS and art. In this second theme we see that through work in their small groups and facilitated discussions with HAICU 
staff and the Michaelis School of Fine Art lecturer, the students were able to start to make the link. One student expressed their view about the process by saying that:

This project was trying to illustrate that the artist's role is not one only of solitary confinement within the studio space. It is also of social responsibility ... to react to these social conditions and illustrate that further for the public to encourage further awareness and conversations of the project. (Focus Group participant 2, Reddy 2012)

This project started to make students aware that training as an artist in today's context motivates one to think about art beyond the confines of the gallery spaces. Working with alternative spaces and temporary artistic gestures opens a range of public interactions that would be framed differently if presented in a 'white cube'. Antonio Valerio was one of the few students who engaged in a solo-performance to address the issues of Masculinity and Stigma (2013). His choice to perform on Jammie Plaza was crucial in creating a space for discussion around sexuality and stigma. This type of disruption of the standard academic timetable and everyday routine was cited as a major strength of the projects in the student feedback. It directs one to think about how artists can intersect with society through artist interjections that propel one to think out of the box.

As this was a first year course students often did not feel that they were equipped with this skill. Students commented that working on the project challenged them to think critically about engaging public spaces and required them to find practical solutions for display and communication (Saptouw 2012). This view was also expressed by another student who indicated how difficult it was to convey the message of HIV related stigma because the student felt that he was not exposed to AIDS and did not experience stigma directly. Through interaction with the staff on the project the student was then directed to think about what it would be like if one was to be treated differently and how this might impact on the way he views the world. This kind of interaction was able to be facilitated through the unique mode of teaching whereby the student is an active participant in his/her learning process. In this space the staff member is a facilitator of knowledge rather than a deliverer of the complete knowledge for the students.

Another student demonstrated this understanding by depicting how his group had interpreted the method of instruction saying that in their project they were showing how: 'Their lives are exactly the same. Everyone has the same things in their cupboards - except the ARVs. We were trying to show the link between someone who is positive and someone who is negative, to show people that they are not different, they are not supposed to be ostracised ...' (Focus Group Participant 3, Reddy 2012, 2). It is evident from this comment 
that students are able to reach the point of intersection between art and a topical area through the method of teaching that the project team chose to employ in this project.

\section{The use of art as a medium to educate students with a specific focus}

When probed specifically in the focus group about how the art students felt about using art as a medium to educate other students on campus, students said that by making the art installations about the topic, the message of HIV related stigma became accessible. By this the art students meant that by inserting a piece of art into daily university life, students were forced to question why it was placed there and how it relates to their everyday lives. The first year students specifically made reference to the fact as this is an educational institution and knowledge is often based on written academic texts, but by placing an art installation in the campus surroundings, students are forced to think about the information they are receiving. Students say that while 'texts are often viewed as finite - art makes you think, makes you engage with it' (Focus Group Participant 4, Reddy 2012, 2). The creation of this knowledge therefore develops organically and students are forced to interact with this lived reality of the campus on that particular day. In the group survey students noted that using art as a method of communication gives students a new lens to view familiar topics (Saptouw 2012).

\section{The method students used to develop art in response to HIV}

In developing the art, the first year students had to think about what medium/method they would use to convey the message about addressing HIV related stigma. This posed many challenges as students needed to think creatively about not only the art as an installation but how the art pieces could contribute to the communication messages on campus for the Candlelight Memorial Day. The art students' comments in the focus group suggested that they had begun to see themselves as not just artists but social commentators. In response to people viewing their art and the emerging role they were playing in this project students commented that 'People were just generally interested in it. Like, a few people would come up and actually ask about it. So I think it was effective in that way, to tell them the message ... engage with them’ (Focus Group Participant 5, Reddy 2012, 2). Another comment by a first year art student which further explained their role was, 'Expressions of people passing by, they were wondering what is going on? ... How does maize represent AIDS? ... How does maize represent stigma? People were walking about calmly by, “Oh wait. Should I step on it?” And “Is it right to step on it?" Some people walked by and then realised and went back. ... Let them form their own links and meaning’ (Focus Group Participant, Reddy 2012, 2). 
In these quotes we can begin to see the students seeing themselves as not only creators of the unique art temporary pieces but as potential key role players in changing the narrative discourse on stigma at the university.

In addition, during the feedback sessions, the students emphasised the value of the social interaction with the viewers. In each project evaluation the students have confirmed that the opportunity to speak to the viewers through a one-on-one interaction is one of the highlights of the HAICU events. Presenting a creative project in a public space that the viewer has to engage with intellectually was regarded as more successful that merely pinning a didactic poster to the notice board (Saptouw 2012).

In summary the pilot project is starting to show how universities may want to engage students on social justice issues in the academic curriculum. Since this initial project UCT has chosen to maintain the inclusion of this content in the first year curriculum, and it is one of the main social responsiveness projects that are run by the Michaelis School of Fine Art UCT. The success of our project encouraged other departments to collaborate with the Michaelis School of Fine Art students. A similar project structure was adopted by the South African Tuberculosis Vaccine Initiative (SATVI), the UCT Green Week Initiative and Michaelis also briefly collaborated with the UCT Disability Unit (Reddy and Saptouw 2015).

\section{CONCLUSION}

With respect to the specific goals of increasing general awareness, promoting reflection and non-discrimination, the communication campaigns and anti-stigma events can be considered a success. The communication campaigns were creative, generated interest and promoted positive messages. For those students who attended the events, the feedback was positive. Within the constraints of a 45-minute meeting, the specific goals were met. Unfortunately, the attendance at these events was relatively small. Institutional barriers limited the reach of these campaigns and events. Attendance was voluntary, during lunch-hour break and might have been in direct competition with other commercial events on campus. The recommendation is to reach a wider audience.

HAICU staff have used the programme theory of an AIDS-competent community as a theoretical framework for its interventions. The HAICU unit campaigns sought to build bonding relationships between itself and students who attended the event, as well as building confidence in local strengths through anti-HIV-stigma campaigns. It is evident from the evaluation that students who did attend the event felt that they mobilise internal bonding relationships. In addition, the teaching module that was piloted in this process has helped to 
build the link between the classroom and the communication messages the university is trying to address. This project has built the foundation for such work and with improvements it can lead to more university students helping to build an inclusive space at the university. However, with respect to the broad goals of an AIDS-competent community, the annual communication events interventions have had limited reach. Of course, there is still a considerable way to go as larger groups of students need to be reached, but the programme theory has enabled structure that is starting to yield results.

\section{REFERENCES}

Campbell, C., Y. Nair, S. Maimane and J. Nicholson. 2007. 'Dying twice': A multi-level model of the roots of AIDS stigma in two South African communities. Journal of Health Psychology 12(3): 403-416.

Campbell, C., M. Skovdal, C. Madanhire, O. Mugurungi, S. Gregson and C. Nyamukapa. 2011. 'We, the AIDS people ...': How antiretroviral therapy enables Zimbabweans living with HIV/AIDS to cope with stigma. American Journal of Public Health 101(6): 1004-1010.

Colle, R. D. 2000. The Enter-Educate approach for promoting social change. Journal of Development Communication. Johns Hopkins University. As quoted by HAICU project officer Sean Brown in March 2008 in a concept note about the HAICU 2008 Stop Stigma campaign.

HAICU see HIV/AIDS Inclusivity and Change Unit.

HEAIDS. 2010. Creating space for HIV and AIDS in the curriculum - A rapid assessment of curricular responses in South African Higher Education institutions. Pretoria: Higher Education South Africa.

HIV/AIDS Inclusivity and Change Unit and Southern Hemisphere. 2009. Youth risk behaviour survey. Unpublished

Joffe, H. 1999. Risk and 'the Other'. London Cambridge University Press.

Johnson, S. 2010. Community Media Trust Evaluation Report. A report on the impact of Siyayinqoba Beat It! on HIV and AIDS. South Africa. Unpublished.

Kleinman, A. 1997. Writing at the margin: Discourse between Anthropology and Medicine. Berkeley and Los Angeles: University of California Press.

Maughan-Brown, B. 2004. Measuring HIV/AIDS stigma. Cape Town: Centre for Social Science Research.

Mendel, G. 2010. The spiral for Gideon Mendel's artwork. http://clarissedesign.com/ portfolio/thespiral-for-david-goldsteins-art-work (accessed 7 April 2016).

Michaelis-HAICU Collaborations. 2012. The HIV stigma project. FIN1005W. Unpublished.

Parker, R. and P. Aggleton. 2002. HIV/AIDS-related stigma and discrimination: A conceptual framework and an agenda for action. Horizons Programme.

Reddy, L. 2012. Focus group Data Report. Cape Town. Unpublished.

Reddy, L. and F. Saptouw. 2015. Social awareness and praxical knowledge. ICAH 2015: 17th International Conference on Arts and Humanities. International Science Index 17(7): 11801184. eISSN: $1307-6892$

Saptouw, F. 2012. Michaelis-Haicu Collaborations - Evaluation/Survey 2012. VULA Online Survey. Unpublished.

Steps for the Future Films. 2016. Steps for our future. http://stepsforthefuture.co.za/ (accessed 4 March 2016). 
Strauss, S. and J. Corbin. 1990. Basics of qualitative research. Newbury park, CA: Sage Publication.

UNAIDS. 2001. Uganda: HIV and AIDS-related discrimination, stigmatisation and denial. Geneva: UNAIDS.

Wienand, A. 2014. Santu Mofokeng: Alternative ways of seeing (1996-2013). In Safundi: The Journal of the South African and American 15(2-3). 